\title{
O CRESCENTE FENÔMENO DA MUTAÇÃO CONSTITUCIONAL E A ATUAÇÃO DO SUPREMO TRIBUNAL FEDERAL NA ADOÇÃO DE NOVAS INTERPRETAÇÕES CONSTITUCIONAIS
}

THE GROWING PHENOMENON OF THE CONSTITUTIONAL MUTA-

TION AND THE ACT OF THE SUPREME FEDERAL COURT IN THE ADOPTION OF NEW CONSTITUTIONAL INTERPRETATIONS

Marina Garcia Faleiros ${ }^{1}$

ISSUE DOI: $10.21207 / 1983.4225 .329$

\section{RESUMO}

Este artigo propõe uma reflexão sobre o crescente fenômeno da mutação constitucional, mecanismo de atualização da Constituição que ocorre por meios informais. Parte de uma pesquisa bibliográfica sobre sua origem e analisa a sua ocorrência por meio de julgados do Supremo Tribunal Federal. Tem como objetivo uma melhor explanação sobre o tema, analisando sua importância frente à realidade social em constante evolução. Busca ainda destacar a atuação do Supremo Tribunal Federal por meio de decisões de altíssima relevância para a sociedade que tiveram como fundamento a mutação constitucional, ponderando a relevância e os riscos de tal

\footnotetext{
${ }^{1}$ Bacharel em Direito pela Faculdade de Direito de Franca/SP; Pesquisadora bolsista pelo Programa Institucional de Bolsas de Iniciação Científica da Faculdade de Direito de Franca (Edital IC-FDF 03/2013), de Setembro/13 até Agosto/14; Pós-graduanda em Direito Tributário pela Faculdade de Direito de Ribeirão Preto FDRP - USP; Advogada.
} 
artifício, além de apontar uma possível solução por meio de atuação conjunta entre os poderes Judiciário e Legislativo.

Palavras-chave: Mutação constitucional. Poder constituinte difuso. Meio informal de alteração da Constituição. Alteração da Constituição sem modificação do texto.

\section{INTRODUÇÃO}

Uma Constituição rígida apresenta um procedimento mais laborioso de alteração do que aquele utilizado na elaboração das leis infraconstitucionais. Essa característica pretende viabilizar a estabilidade das normas constitucionais, pois, uma ordem constitucional instável refletiria na instabilidade do Estado, que teria sua credibilidade questionada.

Diretamente ligada à rigidez se encontra a supremacia constitucional, princípio que firma a superioridade hierárquica da Lex Legum em relação às demais normas componentes do ordenamento jurídico pátrio. Todavia, mesmo rígida e hierarquicamente superior, a Magna Carta prescinde de atualizações face à realidade social cambiante. Quando há necessidade de uma alteração do texto constitucional em razão de modificações no quadro fático sobre o qual incide a norma, da realidade na qual a Constituição está inserida, adota-se a chamada mutação constitucional. Essa mutação pode ainda ocorrer em virtude do surgimento de uma nova visão jurídica que passe a predominar na sociedade. Essa alteração não modifica o texto da lei, que permanece intacto, altera-se apenas o seu sentido, ou seja, muda-se a norma, mas não se muda a letra da lei. Esse novo sentido deve estar em total consonância com os princípios estruturantes da Constituição Federal, apoiado no teor das palavras empregadas pelo constituinte, pois, do contrário abrir-se-ia espaço para uma interpretação inconstitucional.

É muito importante que a Lei Maior do ordenamento acompanhe a realidade social, até mesmo porque a lei existe em função do povo e a ele deve se aplicar de forma a atender às suas necessidades e seus interesses. Entretanto, esse fenômeno informal de alteração constitucional deve ser observado com grande cuidado, atentando-se à real necessidade da alteração e os fins por ela pretendidos, não devendo ser utilizado de forma incoerente, até mesmo porque resulta numa alteração feita, mormente pelo Supremo Tribunal Federal, que não pode e não deve atuar como legislador constitucional. 
Assim, o estudo deste instituto está diretamente ligado à análise do poder constituinte de reforma, que determina o modo como o texto constitucional pode ser formalmente alterado, permitindo, portanto, averiguar as diferenças entre eles.

\section{RIGIDEZ CONSTITUCIONAL, ESTABILIDADE DAS NORMAS CONSTITUCIONAIS E SUPREMACIA DA CONSTITUIÇÃO}

Por rigidez constitucional entende-se o movimento dificultoso de alteração da Constituição. O parâmetro para a aferição dessa dificuldade é o processo legislativo de elaboração das demais leis do ordenamento, ou seja, uma Constituição é considerada rígida quando exige, para a modificação de seu texto, um processo legislativo mais árduo do que o processo de elaboração das demais leis. Rigidez, aqui, nada tem a ver com imutabilidade, o que seria algo totalmente questionável ante o constitucionalismo moderno; o que se pretende, na realidade, é assegurar maior estabilidade ao texto constitucional.

Apesar da ideia de rigidez e flexibilidade das constituições serem bem anteriores, James Bryce, jurista britânico, foi o precursor da formulação clássica desses conceitos ao empregar, pela primeira vez, em sua obra The american commonwealth, os termos rígida e flexível às constituições. $\mathrm{Na}$ Grécia antiga, Aristóteles já fazia a diferenciação entre as normas fundamentais da organização política (politéia) e as normas fundadas na politéia, ordinárias (nomói); já em Roma, somente os juízes especiais tinham permissão para modificar as normas fundamentais. ${ }^{2}$ A rigidez constitucional mostra-se importantíssima frente ao processo de modificação formal do texto constitucional, já enraizada historicamente em diversas civilizações.

A Constituição Federal agrupa as normas que estabelecem e delineiam a organização política e jurídica do Estado. Este conjunto de normas precisa de estabilidade uma vez que a manutenção e longevidade das instituições visam transmitir confiabilidade diante da constância de sua aplicação. A instabilidade da Lex Legum refletir-se-ia na instabilidade do Estado.

\footnotetext{
${ }^{2}$ BULOS, Uadi Lammêgo. Mutação constitucional. São Paulo: Saraiva, 1997, p. 74.
} 
Em contrapartida, estabilidade não é sinônimo de imutabilidade. A Constituição deve se manter em íntima ligação com a evolução e o bem estar social posto que deve acompanhar a realidade do povo ao qual se aplica, pois, segundo Burdeau "uma Constituição não se conserva como um monumento histórico. É explorando as possibilidades que ela oferece aos governantes de agir regularmente que se pode mantê-la entre as regras vivas". Com propriedade, ensina José Afonso da Silva:

A estabilidade das constituições não deve ser absoluta, não pode significar imutabilidade. Não há constituição imutável diante da realidade social cambiante, pois não é ela apenas um instrumento de ordem, mas deverá sê-lo, também, de progresso social. Deve-se assegurar certa estabilidade constitucional, certa permanência e durabilidade das instituições, mas sem prejuízo da constante, tanto quanto possível, perfeita adaptação das constituições às exigências do progresso, da evolução e do bem estar social. ${ }^{4}$

A Constituição Federal de 1988 é do tipo rígida, exigindo para sua modificação, votação em dois turnos nas duas Casas do Congresso Nacional, com aprovação de, no mínimo, três quintos dos integrantes de cada Casa Legislativa. Por meio deste procedimento permite-se que a Constituição seja emendada nos termos de seu artigo 60.

Equivocada é a ideia de que, quanto mais rígida for uma Constituição, maior será a sua estabilidade e permanência. Não há qualquer coerência em se manter uma Constituição rígida, que não se adapte à realidade social, esta que, por sua vez, vive em constante transformação, o que acabaria por resultar no efeito contrário, pois, ao invés de estabilidade ter-seia inaplicabilidade por inadequação. Logo, uma Constituição inaplicável nada mais seria do que letra morta. A estabilidade das normas constitucio-

\footnotetext{
${ }^{3}$ BURDEAU, 1969 apud FERRAZ, Anna Candida da Cunha. Processos informais de mudança da constituição. São Paulo: M. Limonad, 1986. p. 6.

${ }^{4}$ SILVA, José Afonso da. Curso de direito constitucional positivo. 34a Ed., São Paulo: Malheiros, 2011, p.42.
} 
nais só pode ser alcançada a partir de sua adequada aplicação. Compartilham desse entendimento os Professores Vicente Paulo e Marcelo Alexandrino:

O grau de rigidez deve ser suficiente para assegurar uma relativa estabilidade à Constituição, por meio da exigência de processo mais dificultoso para a modificação do seu texto, mas sem prejuízo da necessária atualização e adaptação das normas constitucionais às exigências da evolução e do bemestar social. A rigidez deve, portanto, assegurar essas duas necessidades da Constituição: certa estabilidade e possibilidade de atualização. ${ }^{5}$

Decorrência importantíssima da rigidez é o princípio da Supremacia Constitucional. O processo de alteração da Constituição, mais laborioso que o processo de elaboração das demais leis, emprega à Magna Carta supremacia em relação às demais normas do ordenamento jurídico. As normas constitucionais encontram-se num patamar superior em relação às demais espécies do ordenamento, funcionando como fundamento de validade para estas. Por força da supremacia, nenhuma lei ou ato normativo será válido se não estiver de acordo com a Constituição, devendo, neste caso, ser declarada a sua inconstitucionalidade. Qualquer conflito que ameace o postulado da primazia da Magna Carta fere a Supremacia da Constituição, comprometendo a harmonia do ordenamento.

\section{MUTAÇÃO CONSTITUCIONAL}

O surgimento da mutação constitucional se deu por meio da doutrina alemã, com o jurista Paul Laband, que ao observar relevantes alterações na Constituição alemã de 1871, que pretendiam acompanhar a situação constitucional do império, utilizou o termo verfassungswandel para se referir à mutação constitucional, diferenciando-a da verfassungänderung, que se trata da reforma constitucional. Os apontamentos nesse sentido são do professor Lammêgo Bulos:

5 PAULO, Vicente; ALEXANDRINO, Marcelo. Direito constitucional descomplicado.

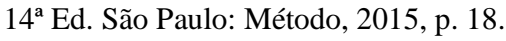


Parece ter sido a doutrina alemã que primeiro detectou o problema, ao notar que a Constituição de 1871 sofria, freqüentemente, mudanças quanto ao funcionamento das instituições do Reich - mudanças estas que ocorriam sem reformas constitucionais. Foi aí que Laband, examinando o aludido texto constitucional alemão de 1871, notou importantes modificações neste Diploma Maior, para acompanhar a situação constitucional do império (verfassungszustand), distinguindo a verfassungänderung (reforma constitucional) da verfassungswandel (mutação constitucional). ${ }^{6}$

A reforma constitucional nada mais é do que o modo formal de alteração da norma, modificando-se o texto da lei. No ordenamento jurídico brasileiro a alteração do texto da Constituição se dá por meio da revisão constitucional ou por meio de emendas à Constituição. As alterações constitucionais formais ocorrem por meio do poder constituinte revisor ou reformador, como se verá adiante.

Existem duas espécies clássicas de poder constituinte, o originário e o derivado. As primeiras linhas da teoria clássica do poder constituinte surgem paralelamente à eclosão da Revolução Francesa (1789), com as ideias de Emmanuel Joseph Sieyès (1748-1836), membro do comitê da Constituição e Presidente da Assembleia francesa. Em sua publicação Que é o Terceiro Estado? (Qu'est-ce que le Tiers État?), Sieyès trabalha com o preceito de que compete à Nação estabelecer a ordem jurídica, pois estaria munida de uma autoridade anterior; em outras palavras, se um povo precisa de uma Constituição, é a Nação que deve fazê-la visto que a Nação existe antes de tudo. Essas leis são fundamentais uma vez que nascem de um poder constituinte, ilimitado e onipotente, e não de um poder constituído. É com Sieyès que surge a distinção formal entre poder constituinte e poder constituído. $^{7}$

Com o correr do tempo, foi possível perceber que, na prática, o poder constituinte se revela de duas maneiras distintas: uma, de formulação

\footnotetext{
${ }^{6}$ BULOS, Uadi Lammêgo. Da reforma à mutação constitucional. Revista de informação legislativa, v. 33, n. 129, p. 25-43, jan./mar. 1996, p. 26. Disponível em: <http://www2.senado.leg.br/bdsf/item/id/176380>. Acesso em: 26/04/2016.

${ }^{7}$ BULOS, Uadi Lammêgo. Mutação constitucional. São Paulo: Saraiva, 1997. p. 12-14.
} 
da Constituição, por meio de um poder criador ilimitado; outra, de alteração formal, para modificar a Magna Carta, resguardadas as devidas limitações. Nota-se, portanto, que o poder constituinte adquire uma função reformadora. Assim, o poder constituinte originário e o poder constituinte derivado seriam, em verdade, duas etapas de um mesmo poder. ${ }^{8}$ Foi daí que surgiram os contornos do que hoje se conhece por poder constituinte originário e poder constituinte derivado.

O poder constituinte originário é aquele por meio do qual se elabora uma Constituição e requer um trabalho mais esmerado do que aquele de criação das demais leis, operando de forma autônoma e incondicionada. Já o poder constituinte derivado é instituído pelo próprio legislador, destinado a reformar a Constituição. Este último traz consigo a função renovadora, atualizando a ordem constitucional instituída pelo poder originário, todavia, deve respeitar os limites previstos na própria Constituição. O poder constituinte derivado pretende a alteração material da Constituição, ou seja, a modificação do texto constitucional, que pode se operar por emenda (art. 60), abrangendo matéria específica adiciona texto novo à Constituição, e, por revisão constitucional, revisando toda a matéria constitucional, a ser realizada uma única vez, após cinco anos, contados da promulgação da Constituição, pelo voto da maioria absoluta dos membros do Congresso Nacional, em sessão unicameral (ADCT, art. $3^{\circ}$ ).

É evidente que as técnicas de alteração constitucional, expressas na Constituição, não são o bastante para atender às necessidades sociais emergentes que clamam pela atualização das normas constitucionais. Afirma Meirelles Teixeira:

Seria errôneo, entretanto, e mesmo ingênuo, pensarse que as Constituições rígidas somente pudessem sofrer alterações através de técnicas jurídicas expressa e previamente estabelecidas, e que o impacto da evolução política e social somente pudesse atuar sobre elas através desses canais, e que a vida deveria necessariamente acomodar-se, em seu eterno fluxo de progresso, dobrando-se com docilidade ao sabor

\footnotetext{
${ }^{8}$ BULOS, Uadi Lammêgo. Mutação constitucional. São Paulo: Saraiva, 1997. p. 19.
} 
dessas fórmulas e apenas ao juízo de políticos e legisladores 9 .

Alguns doutrinadores alegam, também, a existência do chamado poder constituinte difuso, ainda pouco citado pela doutrina brasileira. O poder constituinte difuso seria o responsável pela gênese da mutação constitucional, já que, como o próprio nome aduz, utiliza-se de meios difusos de modificação constitucional, apontando para alterações constitucionais que se operam diversamente daquelas definidas pelo poder reformador. E nesse sentido, "Destina-se a função constituinte difusa a completar a Constituição, a preencher vazios constitucionais, a continuar a obra do constituinte. Decorre diretamente da Constituição, isto é, o seu fundamento flui da Lei Fundamental, ainda que implicitamente, e de modo difuso e inorganizado". ${ }^{10}$

O poder constituinte difuso é um meio informal de alteração da Constituição, que atua no sentido e alcance da norma, ditando qual é a melhor forma de se interpretar determinado dispositivo, sem vulnerar-lhe uma palavra sequer. Essas mudanças informais ocorrem, diferentemente do processo formal de alteração constitucional, sem necessidade de observação dos requisitos e limites expressos instituídos pelo poder originário, "[...] são difusas e inorganizadas, porque nascem da necessidade de adaptação dos preceitos constitucionais aos fatos concretos, de um modo implícito, espontâneo, quase imperceptível, sem seguir formalidades legais".. ${ }^{11}$ A este fenômeno dá-se o nome de mutação constitucional. Vejam-se as considerações dos Professores Vicente Paulo e Marcelo Alexandrino:

É chamado de difuso porque não vem formalizado (positivado) no texto das Constituições. É um poder de fato porque nascido do fato social, político e econômico. É meio informal porque se manifesta por intermédio das mutações constitucionais,

\footnotetext{
9 TEIXEIRA, 1961 apud Ferraz, FERRAZ, Anna Candida da Cunha. Processos informais de mudança da constituição. São Paulo: M. Limonad, 1986. p. 7.

${ }^{10}$ FERRAZ, Anna Candida da Cunha. Processos informais de mudança da constituição. São Paulo: M. Limonad, 1986, p. 10.

${ }^{11}$ BULOS, Uadi Lammêgo. Mutação constitucional. São Paulo: Saraiva, 1997, p. 59.
} 
modificando o sentido das Constituições, mas sem nenhuma alteração do seu texto expresso. ${ }^{12}$

A Constituição Federal é dotada de rigidez, o que exige, para a alteração de seu texto, um processo legislativo mais dificultoso do que o adotado para a criação das demais leis do ordenamento. Essa rigidez pretende atribuir uma maior estabilidade às normas constitucionais, bem como impor-lhes certa supremacia quanto às demais leis do ordenamento. Todavia, esses mecanismos não pretendem impedir pretensas alterações na Magna Carta.

Uma Constituição é resultado da interação das manifestações sociais e aspirações políticas de um povo. Muitas vezes se faz necessária uma alteração da norma tendo em vista as transformações sociais e políticas pelas quais passa a sociedade, transformações estas que podem gerar uma inadequação quanto ao alcance da lei. A mutação surge nesse ínterim para, simplificadamente, realizar as alterações necessárias quanto ao sentido da norma sem que para isso seja necessário alterar-lhe a letra da lei. "Esse novo sentido ou alcance do mandamento constitucional pode decorrer de uma mudança na realidade fática ou de uma nova percepção do Direito, uma releitura do que deve ser considerado ético ou justo". ${ }^{13}$ Não faria qualquer sentido manter uma norma no ordenamento que não possui aplicabilidade, ou que não atinge os fins pretendidos pelo legislador originário quanto à incidência dos princípios constitucionais nos quais esteve embasado. Explicam os Professores Vicente Paulo e Marcelo Alexandrino:

As denominadas mutações (ou transições) constitucionais descrevem o fenômeno que se verifica em todas as Constituições escritas, mormente nas rígidas, em decorrência do qual ocorrem contínuas, silenciosas e difusas modificações no sentido e no alcance conferidos às normas constitucionais, sem que haja modificação na letra de seu texto. Consubstanciam a chamada atualização não formal da Constituição. Em uma frase: ocorre uma mutação

\footnotetext{
12 PAULO, Vicente; ALEXANDRINO, Marcelo. Direito constitucional descomplicado. $14^{\mathrm{a}}$ Ed. São Paulo: Método, 2015, p. 88.

${ }^{13}$ BARROSO, Luis Roberto. Curso de direito constitucional contemporâneo: os conceitos fundamentais e a construção do novo modelo. São Paulo: Saraiva, 2009. p. 125-126.
} 
constitucional quando "muda o sentido da norma sem mudar o seu texto". ${ }^{14}$

A mutação é um meio reconhecido de alteração, desde que, para tanto, mantenha-se pautada nos princípios estruturais da Carta Maior, pois não pretende ferir a rigidez e supremacia constitucionais, mas sim, servir de instrumento para manter a harmonia entre princípios, norma e realidade fática. Ainda que informal, a mutação constitucional é totalmente admitida no cenário jurídico, e mais, "essa admissão, é bem de ver, precisou superar a separação metodológica rígida entre o mundo do Direito (o ser) e a realidade fática (o dever-ser), imposta pelo positivismo jurídico". ${ }^{15}$

J.J. Gomes Canotilho emprega o termo alteração constitucional (Verfassungsànderung), ao se referir ao modelo de revisão formal, resultando em alteração do texto constitucional. Já os termos transições ou mutações constitucionais (Verfassungswandlungen), se referem ao modo de revisão informal segundo o qual se altera o sentido sem alterar-se o texto constitucional. Explica melhor em sua obra, Canotilho:

Antecipando alguma coisa do que será dito a propósito da revisão da constituição, considerar-se-á como transição constitucional a revisão informal do compromisso político formalmente plasmado na constituição sem alteração do texto constitucional. Em termos incisivos: muda o sentido sem mudar o texto. ${ }^{16}$

Jorge Miranda ${ }^{17}$ prefere empregar o termo vicissitudes constitucionais tácitas; estaria assim se referindo às modificações decorrentes do

\footnotetext{
${ }^{14}$ PAULO, Vicente; ALEXANDRINO, Marcelo. Direito constitucional descomplicado. $14^{a}$ Ed. São Paulo: Método, 2015. p. 610.

${ }^{15}$ Hesse, 1983 apud BARROSO, BARROSO, Luis Roberto. Curso de direito constitucional contemporâneo: os conceitos fundamentais e a construção do novo modelo. São Paulo: Saraiva, 2009. p.123.

${ }^{16}$ CANOTILHO, J. J. Gomes. Direito constitucional. 6a Ed. rev. Coimbra: Almedina, 1993, p. 231.

${ }^{17}$ MIRANDA, 1991 apud BULOS BULOS, Uadi Lammêgo. Mutação constitucional. São Paulo: Saraiva, 1997. p. 57.
} 
costume prater e contra legem, juntamente com as resultantes da interpretação evolutiva da Constituição e as revisões indiretas, sendo esta última uma forma particular de interpretação sistemática.

Outros termos foram também empregados, como mudança material, utilizado por Luiz Pinto Ferreira ${ }^{18}$ ao se referenciar pelas lições de Corwin, Cushman, Stier-Somlo, Jellinek e Munro. Mudança material, conforme estes autores, são as modificações constitucionais oriundas dos costumes e da interpretação judicial.

Anna Cândida da Cunha Ferraz ${ }^{19}$ utilizou as expressões processos indiretos, processos não formais ou processos informais, para tratar de qualquer modo de alteração constitucional que não tenha sido realizada por meio do poder derivado.

Vale frisar que, acerca da vasta terminologia empregada por diversos estudiosos do tema, não há qualquer objeção quanto ao emprego de uma ou outra, pois, todas elas pretendem o mesmo fim: fazer menção ao fenômeno de modificação constitucional operada de forma diversa da delimitada pelo poder derivado.

Segundo os ensinamentos do Professor Uadi Lammêgo Bulos, a Constituição estaria sujeita, com o tempo, a novas significações, mesmo sem revisões ou emendas, o que seria possível levando-se em conta o caráter dinâmico da ordem jurídica. Por meio deste caráter dinâmico, tornase possível adequar a norma à realidade fática, empregando-lhe novo sentido. Seria então, um movimento de renovação do alcance da própria Constituição. Observe-se o que ensina o Professor Lammêgo Bulos:

O caráter dinâmico e prospectivo da ordem jurídica propicia o redimensionamento da realidade normativa, onde as Constituições, sem revisões ou emendas, assumem significados novos, expressando uma temporalidade própria, caracterizada por um

\footnotetext{
18 FERREIRA, 1962 apud BULOS, BULOS, Uadi Lammêgo. Mutação constitucional. São Paulo: Saraiva, 1997. p. 58.

${ }^{19}$ FERRAZ, Anna Candida da Cunha. Processos informais de mudança da constituição. São Paulo: M. Limonad, 1986. p. 58.
} 
renovar-se, um refazer-se de soluções, que, muitas vezes, não promanam de reformas constitucionais. ${ }^{20}$

A preocupação quanto à observância dos princípios estruturantes da Constituição é o grande alvo dos doutrinadores, tanto que, a mutação somente se configura como ato legítimo quando ocorre em consonância com tais princípios. Segundo Canotilho, há duas formas de se observar a mutação constitucional, uma delas como sendo um ato legítimo de interpretação constitucional, com a devida observância aos princípios estruturais da Magna Carta. Segundo Canotilho:

A necessidade de uma permanente adequação dialéctica entre o programa normativo e a esfera normativa justificará a aceitação de transições constitucionais que, embora traduzindo a mudança de sentido de algumas normas provocado pelo impacto da evolução da realidade constitucional, não contrariam os princípios estruturais (políticos e jurídicos) da constituição. O reconhecimento destas mutações constitucionais silenciosas ('stillen Verfassungswandlungen') é ainda um acto legítimo de interpretação constitucional. ${ }^{21}$

Já a outra forma de mutação estaria ligada às mudanças radicais de sentido da norma, na tentativa de legitimar uma interpretação que contradiz a Constituição escrita, seria esta uma mutação constitucional inconstitucional. Canotilho deixa claro que: "Perspectiva diferente se deve adoptar quanto às tentativas de legitimação de uma interpretação constitucional criadora que, com base na força normativa dos factos, pretenda "constitucionalizar" uma alteração constitucional em inequívoca contradição com a constitutio scripta". ${ }^{22}$

\footnotetext{
${ }^{20}$ BULOS, Uadi Lammêgo. Da reforma à mutação constitucional. Revista de informação legislativa, v. 33, n. 129, p. 25-43, jan./mar. 1996, p. 25. Disponível em: <http://www2.senado.leg.br/bdsf/item/id/176380>. Acesso em: 26/04/2016.

${ }^{21}$ CANOTILHO, J. J. Gomes. Direito constitucional. $6^{\text {a }}$ Ed. rev. Coimbra: Almedina, 1993, p. 232.

${ }^{22}$ Ibidem.
} 
É preciso, porém, muita cautela para perceber a singela diferença que pode existir entre uma mutação constitucional inconstitucional, que viola a Carta Magna, e uma mutação constitucional que se opera por meio do desenvolvimento do direito constitucional. Não se pode perder de vista a manutenção dos princípios norteadores da Carta Maior a fim de evitar colisões entre a Constituição e a realidade constitucional. As considerações de Anna Cândida são nesse sentido:

A experiência constitucional demonstra que a expressão mutação constitucional, ou seja, os processos não formais de mudança constitucional, não é empregada uniformemente pela doutrina, abrigando, a um só tempo, dois tipo ou espécies diferentes de mutações: as que não violentam a Constituição, isto é, aquelas que, se confrontadas por qualquer meio de controle, particularmente pelo jurisdicional, não sofrerão a pecha de inconstitucionalidade, e as mutações constitucionais que contrariam a Constituição e que, num confronto com a Lei Fundamental, não devem subsistir. ${ }^{23}$

Apesar dessa apresentação multifacetária, este estudo adota, assim como a doutrina majoritária, o termo mutação constitucional como sendo aquele representativo das alterações informais pelos quais passam a Constituição, mantendo-lhe o texto e alterando-lhe o sentido, preservando perfeita consonância com os preceitos e princípios constitucionais basilares.

\section{A IMPORTÂNCIA DA MUTAÇÃO CONSTITUCIONAL}

Acreditou-se, por muito tempo, que uma Constituição poderia ser imutável, eterna, o que lhe traria estabilidade e aplicabilidade. O Código de Hamurabi é um dos maiores exemplos de ideário das constituições permanentes, mas, muito tempo antes, Licurgo já vislumbrava a inalterabilidade das leis, exigindo do povo espartano que jurasse manter imodificadas

${ }^{23}$ FERRAZ, Anna Candida da Cunha. Processos informais de mudança da constituição. São Paulo: M. Limonad, 1986, p. 9. 
as suas leis. ${ }^{24}$ Todavia, hodiernamente, resta pacífico o entendimento de que as Constituições carecem de alterações ante a realidade social cambiante. O constitucionalismo contemporâneo lida pacificamente com a questão da mutação constitucional, a qual atua como instrumento de adequação da norma à realidade vivida em sociedade, que evolui rapidamente com o surgimento de situações novas. É evidente que o legislador constituinte preocupa-se com a manutenção da estabilidade da Constituição visando a sua perpetuação futura, todavia, diante de qualquer Constituição que vigore por um período longo, é inegável a necessidade de sua atualização às novas circunstâncias sociais.

Diante de toda essa temática de atualização e modificação do sentido e do alcance do Texto Constitucional, é importante uma reflexão acerca dos limites da mutação constitucional. Nessa esteira de pensamento fica claro que as mutações constitucionais acompanham a realidade social e suas evoluções, por isto, os limites impostos a esse fenômeno do poder constituinte difuso não seriam passíveis de uma determinação exata. Lammêgo Bulos explica melhor essa questão da impossibilidade de determinação exata dos limites da mutação:

Em verdade, não é possível determinar os limites da mutação constitucional, porque o fenômeno é, em essência, o resultado de uma atuação de forças elementares, dificilmente explicáveis, que variam conforme acontecimentos derivados do fato social cambiante, com exigências e situações sempre novas, em constante transformação. ${ }^{25}$

Com uma visão mais atualizada acerca dos limites da mutação constitucional, Luis Roberto Barroso ${ }^{26}$ aponta para a existência de dois limites: um deles seria o de que a mutação deve ocorrer em observância aos possíveis sentidos do texto que está sendo interpretado ou afetado, ou seja, observa-se a semântica do que prescreve a norma; o outro limite seria o da preservação dos princípios fundamentais vez que são eles os componentes

\footnotetext{
${ }^{24}$ BULOS, Uadi Lammêgo. Mutação constitucional. São Paulo: Saraiva, 1997, p. 12.

${ }^{25}$ Ibidem, p. 88.

${ }^{26}$ BARROSO, Luis Roberto. Curso de direito constitucional contemporâneo: os conceitos fundamentais e a construção do novo modelo. São Paulo: Saraiva, 2009. p. 127.
} 
primeiros de identidade da Constituição. Tais limites são totalmente adequados, não usurpam a atividade necessária de atualização da norma à realidade fática, bem como garantem a coerência e harmonia que devem estruturar o ordenamento jurídico.

A importância da mutação está atrelada à realidade constitucional do País. A Magna Carta guarda grande relação com as transformações que ocorrem freqüentemente na dinâmica social de um determinado povo. Como um manto, a Constituição deve abarcar o maior número possível de relações sociais, políticas e econômicas, de modo que os princípios constitucionais incidam amplamente sobre a realidade social. Ainda que o legislador originário tente agrupar o maior número de possibilidades a serem tuteladas, com o decorrer do tempo será necessária uma renovação, pois, fatos novos surgem, situações antes não previstas, tornam-se constantes, o que pede uma atualização do ordenamento jurídico. É nesse sentido que “[...] a resistência à substituição será inútil, pois os princípios já não bastarão para estancar o fluir de relações inconciliáveis com o quadro ultrapassado". 27

A Constituição, como elemento ligado à transmutação da realidade social, pode ser compreendida, conforme os estudos do Professor Bulos, como um organismo vivo, ligado ao progresso e bem estar social; explica ele:

[...] é possível compreender uma Constituição como um organismo vivo, porque no seu preparo, no ato mesmo da sua criação, é incumbência do legislador prever possíveis modificações futuras, o que exige conferir às normas elasticidade, abrindo perspectivas de recepção de fatos novos, surgidos após o advento do Documento Supremo. ${ }^{28}$

As mutações constitucionais acontecem compassadamente, sem alterações drásticas e escandalizadoras, até mesmo porque as modificações sociais levam certo tempo para se consolidarem, refletindo na ocorrência espontânea e natural das mutações. Vários fatores modificativos da realidade constitucional podem levar à mutação constitucional, como as interpretações dos tribunais, os usos e costumes, e até mesmo a pressão popular

${ }^{27}$ BULOS, Uadi Lammêgo. Mutação constitucional. São Paulo: Saraiva, 1997, p. 6.

${ }^{28}$ Ibidem. 
acerca de determinada matéria. ${ }^{29}$ É no sentido de tornar possível a abrangência da Magna Carta sobre as situações cambiantes da vida real, sobre as incompletudes do Texto Magno, que a mutação surge, como uma decorrência lógica da efetividade e aplicabilidade das normas constitucionais. Deixa claro Anna Cândida:

É uma decorrência lógica da Constituição, na medida em que esta é uma obra que nasce para ser efetivamente aplicada, sobretudo naquilo que tem de essencial, e o essencial, por vezes, é incompleto, exigindo atuação posterior, capaz de defini-lo, precisá-lo, resolver-lhe as obscuridades, dar-lhes continuidade e aplicação, sem vulnerar-lhe a obra constitucional escrita. ${ }^{30}$

É diante da necessidade de adequação da Constituição a essa nova realidade que a mutação constitucional exerce seu papel primordial. Existem três meios de atuação pelos quais pode ocorrer a mutação constitucional, são eles: mutação por interpretação constitucional, mutação pela atuação do legislador e mutação por costume constitucional.

O meio mais usual de mutação constitucional é o que ocorre por vias interpretativas. Levando-se em conta a separação dos poderes do Estado, é fácil perceber que todos eles se valem da interpretação da Lex Legum, ainda que de variadas formas. O Poder Judiciário, por exemplo, deve pautar todas as suas atividades nos princípios constitucionais estruturantes da Constituição Federal, com o fito de atingir com sucesso os fins pretendidos pela sua atividade essencial. Não é diferente o que ocorre com o Poder Executivo e os órgãos ligados à Administração Pública, que, ao articular o meio mais adequado de sua atuação no dia a dia de suas funções, deve interpretar a Constituição. Já o Poder Legislativo atua na criação das leis, portanto, ao passo da função legiferante cabe ao legislador interpretar a Constituição para que não crie leis inconstitucionais. A interpretação realizada pelo legislador será tratada mais adiante, como sendo a mutação por atuação do legislador, competindo à mutação por interpretação apenas às funções judicial e administrativa.

\footnotetext{
${ }^{29}$ BULOS, Uadi Lammêgo. Mutação constitucional. São Paulo: Saraiva, 1997, p. 61.

${ }^{30}$ FERRAZ, Anna Candida da Cunha. Processos informais de mudança da constituição. São Paulo: M. Limonad, 1986, p. 10.
} 
A mutação constitucional por meio de interpretação ocorre quando se muda o sentido da norma, em detrimento do sentido preexistente, ou seja, existe uma interpretação que será alterada, atribuindo novo sentido à norma. A mutação por interpretação ocorrida no Judiciário geralmente se opera quando o Supremo Tribunal Federal atribui sentido diverso do anteriormente fixado a uma norma constitucional, diante de nova realidade social ou nova percepção do Direito. O que ocorre, também, com a interpretação feita pelos órgãos administrativos, que, inclusive, possui referência na legislação infraconstitucional (art. $2^{\circ}, \S$ único, inciso, XIII, da Lei 9.784/99). ${ }^{31}$

Ao legislador compete a função de editar leis que atendam às necessidades sociais. A mutação por atividade do legislador ocorre quando se modifica a interpretação dada anteriormente a uma norma constitucional por meio da edição de uma lei nova. Essa lei nova, modificativa do sentido preexistente, fica sujeita ao controle de constitucionalidade, que irá determinar se a nova interpretação é possível e legítima. É o Supremo Tribunal Federal que tem o condão de determinar a validade da mutação constitucional. $^{32}$

O costume, para ser considerado fonte do direito positivo, precisa contar com a prática reiterada de determinado ato, e essa prática precisa ser reconhecida como válida, e, em algumas situações, como obrigatória. Um costume pode, muitas vezes, estampar em si mesmo uma interpretação informal da Constituição. Um exemplo disso é o relativo aos poderes das Comissões Parlamentares de inquérito (CPIs), as quais tiveram suas competências aumentadas no que tange à determinação de certas providências, como quebra de sigilos bancário, telefônico e fiscal, que antes não eram admitidas. $^{33}$

\section{A ATUAÇÃO DO SUPREMO TRIBUNAL FEDERAL NO CAMPO DA MUTAÇÃO CONSTITUCIONAL}

\footnotetext{
${ }^{31}$ BARROSO, Luis Roberto. Curso de direito constitucional contemporâneo: os conceitos fundamentais e a construção do novo modelo. São Paulo: Saraiva, 2009, p. 130.

32 Ibidem, p. 132-133.

${ }^{33}$ Ibidem, p. 134-135.
} 
É importante a análise da crescente atuação do Supremo Tribunal frente à ocorrência da mutação constitucional e isto se dá porque é ele o órgão responsável por averiguar e vedar qualquer ameaça aos preceitos constitucionais. Todavia, vale a reflexão acerca da extensão dos poderes exercidos pela Suprema Corte, de modo a evitar que sua atuação seja a de um legislador constitucional.

Por meio da análise de alguns julgados da Suprema Corte é perceptível a ocorrência da mutação constitucional como fundamento de decisões que versavam sobre assuntos extremamente relevantes para a sociedade brasileira diante de novas realidades fruto da evolução e do correr do tempo.

A competência da Justiça do Trabalho para as ações acidentárias decorrentes de acidente de trabalho - RE $450504^{34}$ : por meio do julgamento do RE 450.504, o Supremo Tribunal reconheceu a competência da Justiça do Trabalho para as causas que versem sobre as ações acidentárias decorrentes de acidentes de trabalho, alegando a ocorrência de mutação constitucional da jurisprudência da Suprema Corte.

É notório que a competência da Justiça do Trabalho está determinada expressa e limitadamente pelo art. 114, CF, c/c 109, I, CF. O STF aponta que, antes mesmo da redação dada ao art. 114 pela $\mathrm{EC} \mathrm{n}^{\circ} 45$ de 2002, que trouxe um aumento da competência da Justiça do Trabalho, em sua redação original, a competência para tais ações já era da Justiça do Trabalho, todavia, a jurisprudência do STF indicava, naquela época, a competência da justiça comum para julgar tais ações. Desta monta, o STF adotou como marco a $\mathrm{EC} \mathrm{n}^{\circ} 45$ de 2002 como um divisor de águas nessa questão de competência, não para representar uma mudança de competência, mas apenas para evitar a remessa de milhares de processos dessa natureza que se encontravam na justiça comum, os quais continuariam na justiça comum.

Por meio da alegada mutação constitucional da jurisprudência do STF, que previa a competência da justiça comum para as ações em comento, restou fixada a competência da justiça trabalhista. Importa frisar novamente que, conforme a decisão do Supremo, as ações acidentárias decorrentes de acidente do trabalho já eram da competência da Justiça do

\footnotetext{
${ }^{34}$ BRASIL. Supremo Tribunal Federal. RE 450.504. Relator(a): Min. CARLOS BRITTO, Primeira Turma, julgado em 21/11/2006, DJ 02-02-2007 PP- 00116 EMENT VOL-0226209 PP-01836. Disponível em: <http://redir.stf.jus.br/paginadorpub/paginador.jsp?docTP=AC\&docID=402680>. Visto em: 27/04/2016.
} 
Trabalho desde o texto original do art. 114 quando da gênese da $\mathrm{CF} / 88$, apenas a jurisprudência da Corte é que apontava de forma contrária, a qual sofrera mutação, adequando-se a este entendimento. Logo, a EC $\mathrm{n}^{\circ} 45$ de 2002 não trouxe qualquer alteração no nível de competência da Justiça do Trabalho quanto às ações acidentárias, apenas adequou o entendimento jurisprudencial frente ao entendimento da norma constitucional.

A prisão civil por dívida - a revogação da prisão do depositário infiel - HC $96.772^{35}$ : A Constituição em seu art. $5^{\circ}$, inciso LXVII, previu as hipóteses em que é possível a prisão civil por dívida, estando entre elas a prisão do depositário infiel. O STF, no HC 96.772, reconheceu a ilegitimidade jurídica da prisão do depositário infiel em razão da Convenção de Direitos Humanos, da qual o Brasil é signatário, que permite a prisão civil apenas em caso de dívida de pensão alimentícia. Em razão da mutação constitucional, foi revogada a Súmula 619 do STF que permitia a prisão do depositário infiel, pois, ainda que a Convenção Americana de Direitos Humanos não tenha sido recepcionada pelo procedimento de criação das emendas constitucionais, o qual the atribuiria status de norma constitucional, a inserção a colocou numa posição de norma supralegal, estando hierarquicamente acima das normas infraconstitucionais e abaixo da $\mathrm{CF}$. Segundo o voto, a posição de norma supralegal impede que qualquer outra norma infraconstitucional, com ela conflitante, permaneça no ordenamento. Todavia, o $\S 2^{\circ}$, do art $5^{\circ}$, da Magna Carta, determina expressamente que os direitos e garantias fundamentais expressos neste mesmo artigo, não excluem outros decorrentes de tratados internacionais que o Brasil venha a fazer parte, o que traria, de fato, a ilegitimidade jurídica da prisão do depositário infiel vez que se trata de um tratado internacional de direitos humanos. Esse entendimento estaria baseado no corolário de que a garantia dos direitos humanos deve ser sempre observada, principalmente quando traz a ampliação desses direitos. Veja a ementa do referido HC:

"HABEAS CORPUS" -
DEPOSITÁRIO JUDICIAL
- REVOGAÇÃO DA
SÚMULA $619 / \mathrm{STF} \quad-\quad$ A
QUESTÃO DA

\footnotetext{
${ }^{35}$ BRASIL. Supremo Tribunal Federal. HC 96.772. Relator(a): Min. CELSO DE MELLO, Segunda Turma, julgado em 09/06/2009, DJe-157 DIVULG 20-08-2009 PUBLIC 21-082009 EMENT VOL-02370-04 PP-00811 RTJ VOL-00218- PP-00327 RT v. 98, n. 889, 2009, p. 173-183. Disponível em: <http://redir.stf.jus.br/paginadorpub/paginador.jsp?docTP=AC\&docID=601192>. Visto em: 27/04/2016.
} 
INFIDELIDADE DEPOSITÁRIA - CONVENÇÃO AMERICANA DE DIREITOS HUMANOS (ARTIGO $7^{\circ}, \quad$ n. $\quad 7$ ) - NATUREZA CONSTITUCIONAL OU CARÁTER DE SUPRALEGALIDADE DOS TRATADOS INTERNACIONAIS DE DIREITOS HUMANOS? PEDIDO DEFERIDO. ILEGITIMIDADE JURÍDICA DA DECRETAÇÃO DA PRISÃO CIVIL DO DEPOSITÁRIO INFIEL, AINDA QUE SE CUIDE DE DEPOSITÁRIO JUDICIAL . - Não mais subsiste, no sistema normativo brasileiro, a prisão civil por infidelidade depositária, independentemente da modalidade de depósito, tratese de depósito voluntário (convencional) ou cuide-se de depósito necessário, como o é o depósito judicial. Precedentes. Revogação da Súmula 619/STF. TRATADOS INTERNACIONAIS DE DIREITOS HUMANOS: AS SUAS RELAÇÕES COM O DIREITO INTERNO BRASILEIRO E A QUESTÃO DE SUA POSIÇÃO HIERÁRQUICA - - A Convenção Americana sobre Direitos Humanos (Art. $7^{\circ}$, n. 7). Caráter subordinante dos tratados internacionais em matéria de direitos humanos e o sistema de proteção dos direitos básicos da pessoa humana . - Relações entre o direito interno brasileiro e as convenções internacionais de direitos humanos $\left(\mathrm{CF}\right.$, art. $5^{\circ}$ e $\S \S 2^{\circ}$ e $\left.3^{\circ}\right)$. Precedentes . - Posição hierárquica dos tratados internacionais de direitos humanos no ordenamento positivo interno do Brasil: natureza constitucional ou caráter de supralegalidade? - Entendimento do Relator, Min. CELSO DE MELLO, que atribui hierarquia constitucional às convenções internacionais em matéria de direitos humanos. A INTERPRETAÇÃO JUDICIAL COMO INSTRUMENTO DE MUTAÇÃO INFORMAL DA CONSTITUIÇÃO . A questão dos processos informais de mutação constitucional e o papel do Poder Judiciário: a interpretação judicial como instrumento juridicamente idôneo de mudança informal da Constituição. A legitimidade da adequação, mediante interpretação do Poder Judiciário, da própria Constituição da República, se e quando imperioso 
compatibilizá-la, mediante exegese atualizadora, com as novas exigências, necessidades e transformações resultantes dos processos sociais, econômicos e políticos que caracterizam, em seus múltiplos e complexos aspectos, a sociedade contemporânea. HERMENÊUTICA E DIREITOS HUMANOS: A NORMA MAIS FAVORÁVEL COMO CRITÉRIO QUE DEVE REGER A INTERPRETAÇÃO DO PODER JUDICIÁRIO . - Os magistrados e Tribunais, no exercício de sua atividade interpretativa, especialmente no âmbito dos tratados internacionais de direitos humanos, devem observar um princípio hermenêutico básico (tal como aquele proclamado no Artigo 29 da Convenção Americana de Direitos Humanos), consistente em atribuir primazia à norma que se revele mais favorável à pessoa humana, em ordem a dispensar-lhe a mais ampla proteção jurídica . - O Poder Judiciário, nesse processo hermenêutico que prestigia o critério da norma mais favorável (que tanto pode ser aquela prevista no tratado internacional como a que se acha positivada no próprio direito interno do Estado), deverá extrair a máxima eficácia das declarações internacionais e das proclamações constitucionais de direitos, como forma de viabilizar o acesso dos indivíduos e dos grupos sociais, notadamente os mais vulneráveis, a sistemas institucionalizados de proteção aos direitos fundamentais da pessoa humana, sob pena de a liberdade, a tolerância e o respeito à alteridade humana tornarem-se palavras vãs . - Aplicação, ao caso, do Artigo $7^{\circ}$, n. 7, c/c o Artigo 29, ambos da Convenção Americana de Direitos Humanos (Pacto de São José da Costa Rica): um caso típico de primazia da regra mais favorável à proteção efetiva do ser humano. ${ }^{36}$

${ }^{36}$ BRASIL. Supremo Tribunal Federal. HC 96.772, Relator(a): Min. CELSO DE MELLO, Segunda Turma, julgado em 09/06/2009, DJe-157 DIVULG 20-08-2009 PUBLIC 21-082009 EMENT VOL-02370-04 PP-00811 RTJ VOL-00218- PP-00327 RT v. 98, n. 889, 2009, p. 173-183. Disponível em: <http://redir.stf.jus.br/paginadorpub/paginador.jsp?docTP=AC\&docID=601192>. Visto em: 27/04/2016. p. 173-183. 
Resta, então, grande questionamento acerca dos aspectos abordados. Teria sido de fato uma mutação constitucional ou inconstitucional?

O reconhecimento da União Homoafetiva - ADI $4277^{37}$ : na ADI 4277, o STF atuou por meio de mutação constitucional ao atribuir um novo alcance do sentido de família contido no art. 226 , $\$ 2^{\circ}$, da Constituição, podendo, desta forma, o artigo 1723, CC, ao tratar da união estável, ser interpretado conforme a Constituição. Essa manobra reconheceu a união homoafetiva como família. Vejam-se trechos da ementa:

ARGUIÇÃO DE DESCUMPRIMENTO DE PRECEITO FUNDAMENTAL (ADPF). PERDA PARCIAL DE OBJETO. RECEBIMENTO, NA PARTE REMANESCENTE, COMO AÇÃO DIRETA DE INCONSTITUCIONALIDADE. UNIÃO HOMOAFETIVA E SEU RECONHECIMENTO COMO INSTITUTO JURÍDICO. CONVERGÊNCIA DE OBJETOS ENTRE AÇÕES DE NATUREZA ABSTRATA. JULGAMENTO CONJUNTO. Encampação dos fundamentos da ADPF n ${ }^{\circ} 132-R J$ pela ADI n ${ }^{\circ}$ 4.277$\mathrm{DF}$, com a finalidade de conferir "interpretação conforme à Constituição" ao art. 1.723 do Código Civil. Atendimento das condições da ação. 2. PROIBIÇÃO DE DISCRIMINAÇÃO DAS PESSOAS EM RAZÃO DO SEXO, SEJA NO PLANO DA DICOTOMIA HOMEM/MULHER (GÊNERO), SEJA NO PLANO DA ORIENTAÇÃO SEXUAL DE CADA QUAL DELES. A PROIBIÇÃO DO PRECONCEITO COMO CAPÍTULO DO CONSTITUCIONALISMO FRATERNAL. HOMENAGEM AO PLURALISMO COMO VALOR SÓCIO-POLÍTICO-CULTURAL. LIBERDADE PARA DISPOR DA PRÓPRIA SEXUALIDADE, INSERIDA NA CATEGORIA DOS DIREITOS FUNDAMENTAIS DO INDIVÍDUO, EXPRESSÃO QUE É DA

\footnotetext{
${ }^{37}$ BRASI. Supremo Tribunal Federal. ADI 4277, Relator (a): Min. AYRES BRITTO, Tribunal Pleno, julgado em 05/05/2011, DJe-198 DIVULG 13-10-2011 PUBLIC 14-10-2011 EMENT VOL-02607-03 PP-00341 RTJ VOL-00219- PP- 00212. Disponível em: $<$ http://redir.stf.jus.br/paginadorpub/paginador.jsp?docTP=AC\&docID=628635>. Visto em: 27/04/2016.
} 
AUTONOMIA DE VONTADE. DIREITO À INTIMIDADE E À VIDA PRIVADA. CLÁUSULA PÉTREA. [...] 3. 3. TRATAMENTO CONSTITUCIONAL DA INSTITUIÇÃO DA FAMÍLIA. RECONHECIMENTO DE QUE A CONSTITUIÇÃO FEDERAL NÃO EMPRESTA AO SUBSTANTIVO "FAMÍLIA" NENHUM SIGNIFICADO ORTODOXO OU DA PRÓPRIA TÉCNICA JURÍDICA. A FAMÍLIA COMO CATEGORIA SÓCIO-CULTURAL E PRINCÍPIO ESPIRITUAL. DIREITO SUBJETIVO DE CONSTITUIR FAMÍLIA. 18 ADI 4277, Relator(a): Min. AYRES BRITTO, Tribunal Pleno, julgado em 05/05/2011, DJe-198 DIVULG 13-10-2011 PUBLIC 14-10-2011 EMENT VOL-02607-03 PP-00341 RTJ VOL-00219- PP- 00212 NOGUEIRA, Alexandre de Castro. A mutação constitucional como instrumento do stf para atuar como legislador positivo: a necessidade de um controle externo às modificações constitucionais realizadas por meio da interpretação. Revista Eletrônica Direito e Política, Programa de PósGraduação Stricto Sensu em Ciência Jurídica da UNIVALI, Itajaí, v.10, n.4, $3^{\circ}$ quadrimestre de 2015. Disponível em: www.univali.br/direitoepolitica ISSN 1980-7791. 2267 INTERPRETAÇÃO NÃOREDUCIONISTA. [...]. 4. UNIÃO ESTÁVEL. NORMAÇÃO CONSTITUCIONAL REFERIDA A HOMEM E MULHER, MAS APENAS PARA ESPECIAL PROTEÇÃO DESTA ÚLTIMA. FOCADO PROPÓSITO CONSTITUCIONAL DE ESTABELECER RELAÇÕES JURÍDICAS HORIZONTAIS OU SEM HIERARQUIA ENTRE AS DUAS TIPOLOGIAS DO GÊNERO HUMANO. IDENTIDADE CONSTITUCIONAL DOS CONCEITOS DE "ENTIDADE FAMILIAR" E "FAMÍLIA". [...]. 6. INTERPRETAÇÃO DO ART. 1.723 DO CÓDIGO CIVIL EM CONFORMIDADE COM A CONSTITUIÇÃO FEDERAL (TÉCNICA DA "INTERPRETAÇÃO CONFORME"). RECONHECIMENTO DA UNIÃO HOMOAFETIVA COMO FAMÍLIA. PROCEDÊNCIA DAS AÇÕES. Ante a possibilidade de interpretação em sentido preconceituoso ou 
discriminatório do art. 1.723 do Código Civil, não resolúvel à luz dele próprio, faz-se necessária a utilização da técnica de "interpretação conforme à Constituição". Isso para excluir do dispositivo em causa qualquer significado que impeça o reconhecimento da união contínua, pública e duradoura entre pessoas do mesmo sexo como família. Reconhecimento que é de ser feito segundo as mesmas regras e com as mesmas consequências da união estável heteroafetiva.

É possível perceber, mediante a complexidade do tema abordado pela ADI 4722, a importância da mutação constitucional frente à realidade social, entretanto, é notório como este instituto atribui grande poder ao $\mathrm{Su}-$ premo Tribunal Federal.

A competência do Senado Federal - artigo 52, X, CF/88 - Reclamação 4335AC ${ }^{38}$ : o julgamento da Reclamação 4335 AC causou um grande impacto na esfera jurídica ao discutir a competência atribuída pela Constituição ao Senado Federal no que diz respeito à faculdade de suspender a execução, no todo ou em parte, de uma lei que tenha sido declarada inconstitucional por decisão definitiva do Supremo Tribunal em sede de controle difuso de constitucionalidade.

É evidente que a declaração de inconstitucionalidade por via difusa opera efeito intra partes, abrangendo apenas o caso concreto em questão, todavia, mediante decisão definitiva do STF sobre a inconstitucionalidade de lei ou de parte da lei no caso concreto, pode o Senado Federal suspender a execução, no todo ou em parte, desta lei. Isto ocorre porque, o Senado, como representante do povo, teria o poder-dever de analisar a importância de suspender a execução de uma lei ou de parte dela frente uma inconstitucionalidade que tenha sido declarada por via incidental; esse poder todo tem a ver com a participação do povo, por meio de seus representantes, mediante uma decisão que não pode ser deixada única e exclusivamente nas mãos do poder Judiciário.

\footnotetext{
${ }^{38}$ BRASIL. Supremo Tribunal Federal. Rcl 4335-AC, Relator(a): Min. GILMAR MENDES, Tribunal Pleno, julgado em 20/03/2014, DJe-208 DIVULG 21-10-2014 PUBLIC 2210-2014 EMENT VOL-02752-01 PP-00001.Disponível em: $<$ http://redir.stf.jus.br/paginadorpub/paginador.jsp?docTP=AC\&docID=630101>. Visto em: 28/06/2016.
} 
A maioria dos ministros entende que nos últimos anos as decisões do STF por via de controle difuso têm-se revestido de eficácia expansiva, ou seja, o entendimento é de que se mostra coerente a aplicação dos efeitos do controle concentrado de constitucionalidade a esses casos, sem, todavia, que o Senado decida pela suspensão ou não da lei. Nesse sentido, a competência do Senado seria apenas a de dar publicidade às decisões da Suprema Corte, o que, por sua vez, entra em embate com a literalidade da Lex Legum, e mais, com a própria intenção do legislador originário, que pretendeu, claramente, atribuir ao Senado o poder de decidir sobre a suspensão ou não da lei tida como inconstitucional no caso concreto. Segundo a decisão dos ministros do Supremo Tribunal, o artigo 52, inciso X, teria sofrido mutação, de modo que a correta interpretação seria a de que, compete ao Senado Federal dar publicidade à inconstitucionalidade de lei ou parte de lei assim declarada por decisão definitiva do Supremo Tribunal.

É de suma importância que o ordenamento jurídico esteja em harmonia com a realidade social, de modo a evitar a imutabilidade da Constituição, o que acabaria por resultar em sua inaplicabilidade e inutilidade. Mas, retirar a participação do Senado Federal do controle difuso de constitucionalidade, atribuição que lhe fora dada pela Carta Magna de 1988, seria uma forma de usurpação de competência por parte do Supremo Tribunal Federal, pois, estaria retirando poderes de um órgão Legislativo. Isto nada mais seria do que um desrespeito ao princípio da separação dos poderes, sobrepondo-se o poder Judiciário sobre o poder Legislativo mediante quebra de competência originária deste último sem que haja, ao menos, regulamentação normativa sobre tal fato.

\section{CONSIDERAÇÕES FINAIS}

O estudo da mutação constitucional permite vislumbrar a importância e a complexidade deste fenômeno. A Constituição, ainda que rígida, visando um ordenamento jurídico estável, não pode deixar de atender às necessidades do povo, pois, se assim fosse, acabaria por ser um inútil pedaço de papel, desatualizado e inaplicável. É inegável a relevância da atualização das normas constitucionais com o fito de compatibilizar o direito posto e a realidade social cambiante. Muitas vezes o passar dos anos traz 
consigo evoluções que sugerem a renovação de conceitos e costumes, empregando-lhes cores novas, o que acaba por exigir da ordem jurídica vigente uma reciclagem para que haja a devida adequação entre elas.

Em contrapartida, deve-se refletir sobre o poder concentrado no Supremo Tribunal Federal quando se busca atualizar o sentido do texto constitucional, resultando em uma verdadeira mutação constitucional. Não se trata apenas de aplicar esse ou aquele significado a um caso concreto, trata-se de operar uma mutação de sentido, de interpretação de determinado trecho da Constituição Federal, e é exatamente por este motivo que toda e qualquer mutação deve ter embasamento no propósito do legislador originário ao elaborar tal redação. A repaginação da interpretação do texto constitucional deve estar intimamente ligada ao intuito pretendido pelo legislador constituinte no momento da elaboração da Carta, a letra da Lei Maior não pode se sobrepor ao fato da vida que deve ser tutelado, por isto, não sendo viável a alteração da Lei, é preciso alterar-lhe o significado por meio de nova interpretação. Qualquer mutação constitucional apartada desse suposto limite significa uma afronta aos preceitos e princípios norteadores da Constituição. É por meio da decisão dos ministros do Supremo Tribunal, firmando a aplicação da mutação constitucional, que uma palavra, um trecho ou todo um dispositivo recebe nova roupagem interpretativa, refletindo em toda a sociedade as consequências desse novo sentido adotado, seja ele bom ou ruim.

Finalmente, é imperioso ressaltar a importância do respeito à separação de poderes do Estado, evitando desvio e acúmulo de poderes em uma ou outra esfera. É nesse sentido que o presente estudo aponta como uma solução, a atuação conjunta entre os poderes Judiciário e Legislativo. Caberia ao Judiciário fundamentar seu entendimento favorável à mutação quando determinada demanda lhe permitir chegar a tal conclusão, e, em um segundo momento, o Legislativo atuaria, como representante do povo, decidindo se concorda ou não com o posicionamento da Suprema Corte, se a proposta de mutação for aprovada pelo Legislativo, resta pacífica e consolidada a adoção da nova interpretação constitucional. A participação do poder Legislativo no que tange à adoção de uma nova interpretação constitucional se revela como um condão de validação de tal medida, isto porque todo o processo de criação e votação das leis, inclusive da Constituição, só pode ser exercido pelos representantes eleitos do povo, mediante atribuição de competência que a própria Carta Magna lhe atribuíra. Adotar uma nova interpretação seria uma forma indireta de reconstruir a lei. $\mathrm{O}$ equilíbrio por meio da atuação do Judiciário e do Legislativo apresenta-se 
como uma alternativa moderada frente à necessidade de atualização da Constituição, sem, contudo, usurpar competência do Legislativo, visando ao final o bem estar da sociedade e um ordenamento jurídico coeso, harmônico e atual.

\section{REFERÊNCIAS BIBLIOGRÁFICAS}

BARROSO, Luis Roberto. Curso de direito constitucional contemporâneo: os conceitos fundamentais e a construção do novo modelo. São Paulo: Saraiva, 2009.

BRASIL. Supremo Tribunal Federal. ADI 4277, Relator(a): Min. AYRES BRITTO, Tribunal Pleno, julgado em 05/05/2011, DJe-198 DIVULG 13-10-2011 PUBLIC 14-10-2011 EMENT VOL-0260703 PP-00341 RTJ VOL-00219- PP- 00212. Disponível em:<http://redir.stf.jus.br/paginadorpub/paginador.jsp?docTP $=\mathrm{AC} \&$ docID=628635> . Visto em: 27/04/2016.

. Supremo Tribunal Federal. HC 96.772, Relator(a): Min. CELSO DE MELLO, Segunda Turma, julgado em 09/06/2009, DJe-157 DIVULG 20-08-2009 PUBLIC 21-08-2009 EMENT VOL-0237004 PP-00811 RTJ VOL-00218- PP-00327 RT v. 98, n. 889, 2009, p. 173-183.

Disponível em:<http://redir.stf.jus.br/paginadorpub/paginador.jsp?docTP $=A C \&$ docID=601192>. Visto em: 27/04/2016.

Supremo Tribunal Federal. RE 450.504, Relator(a): Min. CARLOS BRITTO, Primeira Turma, julgado em 21/11/2006, DJ 02-02-2007 PP- 00116 EMENT VOL-02262-09 PP-01836. Disponível em:<http://redir.stf.jus.br/paginadorpub/paginador.jsp?docTP $=\mathrm{AC} \&$ docID=402680 $>$. Visto em: 27/04/2016.

BULOS, Uadi Lammêgo. Da reforma à mutação constitucional. Revista de informação legislativa, v. 33, n. 129, p. 25-43, jan./mar. 1996, p. $26 . \quad$ Disponível em: <http://www2.senado.leg.br/bdsf/item/id/176380>. Acesso em: 26/04/2016.

. Mutação constitucional. São Paulo: Saraiva, 1997.

CANOTILHO, J. J. Gomes. Direito constitucional. $6^{\text {a }}$ Ed. rev. Coimbra: Almedina, 1993. 
FERRAZ, Anna Candida da Cunha. Processos informais de mudança da constituição. São Paulo: M. Limonad, 1986.

PAULO, Vicente; ALEXANDRINO, Marcelo. Direito constitucional descomplicado. 14a Ed. São Paulo: Método, 2015.

SILVA, José Afonso da. Curso de direito constitucional positivo. $34^{\mathrm{a}}$ Ed., São Paulo: Malheiros, 2011. 